\title{
AS NUANCES DA EDUCAÇÃO ESCOLAR: CULTURA, ESTRUTURA E FUNCIONAMENTO DA UNIDADE ESCOLAR ${ }^{1}$
}

\author{
STRUCTURE AND THE NUANCES OF SCHOOL EDUCATION: CULTURE, \\ FUNCTIONING OF THE SCHOOL UNIT
}

ROGÉRIO RODRIGUES 1.

ORCID: https://orcid.org/0000-0003-2657-7302

O Melhor Professor da Minha Vida (Les Grands Esprits). Direção: Olivier Ayache Vidal. Produção: Alain Benguigui e Thomas Verghaeghe. França: 2017. 106 minutos.

O filme francês intitulado Les Grands Esprits, cuja tradução para o português foi O Melhor Professor da Minha Vida, do diretor Oliver Ayache-Vidal, parece apresentar, nessa tradução, um significado específico sobre a trama interessante que transcorre quando um professor renomado de literatura francesa, chamado François Foucault, interpretado por Denis Podalydès, que dá aula numa escola no centro de Paris, é transferido para outra escola na periferia da cidade. Nesse lugar, longe do centro da cidade, o Prof. François Foucault encontra o aluno Seydou Ndombele Wampasi, interpretado por Abdoulaye Diallo, imigrante pobre e com dificuldades de aderir à cultura letrada francesa, mas que encontra na figura desse professor a possibilidade de entrar no mundo da cultura escolar.

A transferência de escola do professor François Foucault ocorre em decorrência de sua própria hipótese pedagógica de que os alunos da periferia não aprendem porque os melhores professores não estão lá para ensinar. Nesse clima de otimismo pedagógico é que o filme representa, em parte, as ilusões das pedagogias modernas, que inventam os seus próprios mitos e saídas para justificar as soluções aos diversos problemas de aprendizagem. É possível reafirmar, neste momento que:

\footnotetext{
'Universidade Federal de Itajubá, Instituto de Física e Química, Itajubá, MG, Brasil.

"Mestre e doutor em Educação pela Faculdade de Educação da Universidade Estadual de Campinas (UNICAMP). Pós-doutor em Filosofia da Educação pela Faculdade de Educação da Universidade de São Paulo (USP). Professor e pesquisador do mestrado em Desenvolvimento, Tecnologias e Sociedade da Universidade Federal de Itajubá (UNIFEI). Professor das disciplinas do curso de licenciatura do Instituto de Física e Química da Universidade Federal de Itajubá (UNIFEI). E-mail: < rrunifei@hotmail.com>.
} 
Não faltam explicações "pedagógicas" para compreender o "aluno anormal", mais propriamente, o "fracasso escolar", as quais centram-se na tese de uma falta de adequação, ou relação natural, entre a intervenção do adulto e o estado psicomaturacional das crianças e dos jovens. Assim, oscila-se entre afirmações do tipo ‘ainda não está maduro para uma tal atividade' e o 'método utilizado revelou ser pouco eficaz' [...].. Sendo essa tese da conaturalidade que funciona como algoritmo do raciocínio pedagógico [...] (LAJONQUIÈRE, 1999. p. 28).

Nesse campo do cientificismo pedagógico, o departamento de Educação da França tem conhecimento de que Prof. Foucault pensa que o problema educacional pode ser resolvido pela presença de professores mais capacitados e experientes em lugares com problema de ensino. Essa proposição atende a uma demanda do referido departamento de educação que solicita a colaboração do professor para a comprovação cartesiana como uma hipótese a ser confirmada, para constituí-la como um plano de governo para que outros professores capacitados possam ser transferidos sem o agravante de protestos. Portanto, o problema do departamento de educação francês é que, antes de transferir professores competentes para a periferia de Paris, precisa ter a certeza de que isso é algo que está devidamente comprovado e constatado a partir do relatório da experiência educacional do Prof. Foucault, após um ano de trabalho com esses alunos da periferia e, principalmente, na obtenção de algum resultado da sua presença como professor desses alunos que não aprendem corretamente o ensinamento escolar.

$\mathrm{Na}$ escola do centro, o professor François Foucault atua de forma completamente exigente e competente, pois, ao entregar a prova aos alunos, posiciona-os como incapazes de aprender algo, devendo estes buscar estudar mais para fazer algo melhor. Apresentase completamente rígido numa conversa com um pai de aluno, que lhe implora para que seu filho faça uma segunda prova, pois tirou nota zero por estar colando.

Ao chegar à escola da periferia, ele encontra outra realidade, pois alguns professores afirmam que os alunos não aprendem pelo simples fato que eles não querem saber nada. $\mathrm{O}$ conselho que recebe do colega de trabalho é que, no primeiro dia de aula, deve se impor, pois "se não fizer isso, eles vão devorar você. Eles são carnívoros!".

Isso se apresenta como uma mensagem segundo a qual, para ser professor, é preciso se impor pela força. Entretanto, para o início de trabalho do professor competente, impõem-se novos contornos, em que o uso da força se apresenta sem resultado algum, uma vez que os alunos contestam sua prática educativa exigente. A história do 
ensinar acaba por se apresentar de outras maneiras, pois a competência e exigência acabam por se defrontar com outras dimensões da vida e da cultura local de diversos imigrantes de países pobres da África. Sendo assim, ele passa a compreender que a chave para o aprender é mostrar para os alunos o gosto pela cultura francesa, alheia aos seus costumes e que tem o seu valor de entendimento pela própria vida.

Nesse processo formativo, o Prof. Foucault acaba se percebendo numa invenção de si mesmo como professor, encontra outro caminho no ensinar e, de modo inédito, começa a inventar o fazer educativo de modo inverso do que fazia na escola do centro. Ele permite que os alunos procedam de modo alheio às atividades escolares, ao identificar que dois colegas de sala conseguem saber antecipadamente as questões da prova escolar. O professor aposta na ideia de que, mesmo sabendo a questão da prova, eles também devem estudar e, portanto, isso se constitui em outra forma que rompe com a repressão institucional e ele passa a compreender que esse copiar também se constitui como um modo de aprender algo no campo da cultura; por isso passa a valorizar todos os esforços dos alunos com elogios, mesmo que seu alcance não seja perceptível no campo institucional escolar.

$\mathrm{Na}$ sua perspectiva de professor, ele começa a estabelecer outra representação do aluno que, mesmo destituído de valor perante a instituição escolar, pode, de fato, aprender algo no campo da cultura. A partir desse momento, Foucault começa a questionar os dispositivos educacionais, mais propriamente, o conselho disciplinar (CD), que suspendem ou expulsam os alunos das escolas. Ele não compreende os motivos de suspensão ou expulsão de alunos que muito precisam da escola como um lugar de aprender as coisas da cultura.

O aluno que mais o contestava em sala de aula, Seydou, estabelece com François Foucault uma trama secreta que os aproximam quando o professor o orienta, como se deve proceder na conquista de uma colega de sala. Os conselhos do prof. François Foucault são no sentido de que, para conquistar o amor da colega, ele deve fazer algo marcante e logicamente isso passa pelo campo do aprender a língua francesa e fazer poemas.

O próprio François Foucault também se envolve afetivamente com uma colega de trabalho, que passa a admirá-lo pelo modo como trabalha como professor. Aqui, a trama do filme alcança um ponto interessante, pois tanto o aluno quanto o professor estão marcados, por um lado, pela tentativa da conquista e, por outro, pela tentativa dos seus desempenhos, cujo truque é fazer algo diferente, que seja pela expressão do poema. 
No passeio pelo museu de Louvre, Maya Diallo (Tabono Tandia) e Seydou se envolvem numa brincadeira que se torna uma aventura, ao se esconderem no dormitório para fazer uma self na cama do rei, e isso acaba desembocando na suspensão de Maya e na expulsão de Seydou no CD da escola. Nesse momento, toda a incompreensão de François Foucault se revela novamente e ele consegue reverter a expulsão de Seydou, ao perceber que o dispositivo escolar não respeita suas própria regras, exigindo, assim, o retorno do aluno por parte da direção da escola.

Ao final de filme, François Foucault consegue o reingresso do aluno expulso, Seydou, e sentados lado a lado, contemplando uma festa de encerramento do ano escolar, o aluno deixa transparecer o resultado de toda a experiência e que pode sentir saudade pela separação causada pela partida do professor em retorno à escola do centro.

O aluno começa a se interessar em estudar na escola do centro e pergunta quanto tem que estudar para ingressar lá, e acaba por declarar algo que não queria dizer: "O senhor vai fazer falta". Nessa trama, o que se revela é que:

(...) todo mestre foi alguma vez aprendiz, ele não passa de um devedor. Pois bem, por que o mestre ensina? Aquilo que ensina é uma amostra "de que" e "do que" deve. Em outras palavras, aquilo que o mestre mostra, para assim educar o aprendiz de plantão, é a prova de seu dever. Em suma, o mestre ensina porque afinal de contas esse é seu dever. (...) O mestre não pode não ensinar o que aprendeu, uma vez que o apre(e)ndido leva consigo um pecado de origem, qual seja, o de uma dívida que, embora reconhecida, não pode de fato ser saldada (LAJONQUIÈRE, 1999, p. 173-4).

Nesse envolvimento, o ponto final do filme torna-se a possibilidade de compartilharem as mesmas piadas, ao corrigir o francês na fala de uma menina que se aproxima para pegar uma bola que jogou perto do professor e diz: "Me desculpe, senhor". No mesmo momento, ele a corrige e diz: "eu gostaria de pedir desculpas". A menina não entende que se trata de uma correção e responde: "Não! Eu que peço desculpas". Os dois começam a rir da falta de entendimento que se estabelece na linguagem e, portanto, fica claro que essa disjunção na compreensão da língua seria a raiz que se estabelece na amizade entre o professor e o aluno no caminho a se percorrer para o aprendizado no campo da cultura escolar.

A amizade consiste em haverem sido mordidos e feridos pelo mesmo, haverem sido inquietados pelo mesmo. Por isso, não poderá entrar na comunidade cúmplice dos leitores aquele que não tenha sentido a mordida do texto. E, também por isso, aquele que tenha sido mordido, não quererá falar com ninguém que não tenha 
passado pelo mesmo que ele passou. E se a condição de professor é que já tenha sido mordido, não será isso - a cumplicidade dos mordidos, dos envenenados, dos que compartilham a mesma mania e o mesmo delírio - o que professor busca na lição? (LARROSA, 2004, p. 145).

Aqui se encontra o ponto circunstancial do sucesso do Prof. François Foucault com o seu o aluno Seydou, em que o processo formativo seria compartilhar dos mesmos conceitos no campo da cultura que se apresentam como elementos identificatórios que se estabelecem na amizade entre aqueles que foram mordidos pelo veneno do saber, pois o aluno rebelde diz algo que não queria confessar: que vai ter saudade do professor.

\section{REFERÊNCIAS}

LAJONQUIÈRE, Leandro de. Infância e Ilusão (Psico). Pedagógicas: escritos de psicanálise e educação. Petrópolis: Vozes, 1999.

LARROSA, Jorge. Pedagogia Profana: danças, piruetas e mascaradas. Trad. Alfredo VeigaNeto. Belo Horizonte: Autêntica, 2004.

\section{NOTAS}

${ }^{1}$ Agradecimento à Universidade Federal de Itajubá (UNIFEI) e ao Prof. Dr. Leandro de Lajonquière da Faculdade de Educação da Universidade de São Paulo (USP).

Submetido: $14 / 09 / 2018$

Aprovado: 19/01/2019

Contato:

Universidade Federal de Itajubá (UNIFEI)

Instituto de Física e Química Av. BPS, 1303, Bairro Pinheirinho Itajubá $|\mathrm{MG}|$ Brasil Caixa Postal 50 CEP 37.500-903 